PROMPTING THE POETIC MUSE:

\title{
THE COMPUTER-ASSISTED TRANSLATION OF BIBLICAL POETRY, WITH SPECIAL REFERENCE TO SONG OF SONGS 8:5B-7 IN CHEWA ${ }^{1}$
}

\author{
Ernst Wendland \\ Faculty of Theology \\ Stellenbosch University
}

\begin{abstract}
How can the digital mind of the computer come to the aid of Bible translators in the field as they carry out their work? To be more specific, is this technical resource and its associated electronic toolkit able to offer any assistance when dealing with some of the most challenging texts of Scripture, namely those written in the form of classical Hebrew poetry? I will address certain aspects of these and related issues by means of a "case study" of the translation of a poetic passage, namely the climactic little love lyric found in Song of Songs (SoS) 8:5b-7. Several major respects in which computer assisted technology (CAT) becomes critically essential for this creative task will be pointed out as we go along. I will focus on the compositional task - that is, upon demonstrating a progressive and systematic computer-assisted generation of a poetic translation. This procedure is illustrated and displayed in relation to the focal passage by means of a number of examples in Chewa that will hopefully offer readers more of an actual "feeling" for the experience of this formally dynamic, but semantically controlled manner of Bible translation in a major Bantu language. In conclusion, I offer several suggestions regarding the implications of this brief study for translator-training programs, as well as for further research and testing in the field of computer-aided and guided translations of the poetic texts of the Scriptures.
\end{abstract}

Keywords: Bible Translation, Computer Technology, Hebrew Poetry, Song of Songs, Chewa, Translator Training, Discourse Analysis

\section{Preview: How can 'CAT' help the 'Muse'?}

One significant area of applying computer assisted technology (CAT) to Bible translation lies in developing a suitable indigenous oral or literary prototype in the target language (TL), one that may be employed as a model to stimulate and guide the activity of composing a functionally equivalent poetic text. Use of the great storage and sorting capacity of a computer permits the collection, easy access, close analysis, and intertextual comparison of data in a systematic and highly specific way when translating the original source language (SL) document into an appropriate poetic form in a given vernacular.

The present study builds for the most part on information that was painstakingly collected in the traditional copy, cut, sort, and paste method (Wendland 1993), but a word

\footnotetext{
This is a revision of a paper originally presented at the International Conference on Translating with Computer-Assisted Technology (ICT-CAT): Changes in Research, Teaching, Evaluation, and PracticeUniversity of Rome "La Sapienza" (April 14-16, 2004).
} 
processor did assist in a final text evaluation and some selective feature-comparison work. I will suggest several ways in which this procedure could have been improved both quantitatively and qualitatively through the use of a computer (namely, the corpus-based approach to translation; see Baker 1995; Bowker 2000; Kenny 2001). The intended result is a vernacular template, or idealized poetic pattern, that may be employed for the purposes of inspiration and/or imitation as translators seek to reproduce the Scriptures in their mother tongue.

A computer thus makes possible the immediate and rapid manipulation of a given text in order to "poeticize" it in various respects and in an interactive manner, one device in relationship with another, depending on the "cotex" and context - including the prevailing socio-cultural setting of the designated audience. In Chewa (technically Chichewa), a major southeastern African language (ca. 12 million speakers), such creative activity, whether intuitive or imitative, may be manifested with respect to the phonology (e.g., alliteration, assonance, rhythm, rhyme), syntax (e.g., ellipsis, forward or backward transposition, parallelism, transitions), the lexicon (e.g., idioms, figurative language, intensifiers, ideophones), and discourse structure (e.g., line/strophe length, balance, symmetry, text segmentation). My application of a more dynamic, or mediated, literary (and oratorical) translation technique is exemplified by means of a progressively varied rendition of the sample passage from chapter 8 of Song of Songs (SoS), which was chosen due to its especially vivid lyric and emotive qualities, coupled with its prominent referential and thematic content (cf. Wendland 1995).

After a brief analysis of this focal pericope, several different degrees of Chewa poetic reformulation will be presented to illustrate some of the great variation that is possible, depending on the desired purpose (skopos) of the envisaged version, as designated by the project's overall job description (brief). In this case, the primary communicative objective is a more vibrant and idiomatic ("domesticated") rendering in terms of structure and style, in keeping with its intended audience, i.e., an urban Zambian Christian youth group with musical and dramatic aspirations. The end-product of this text generation exercise will be accompanied by a number of explanatory notes. These may act as a partial commentative "protocol" to suggest the manner in which a translator or redactor (in this case, the present author) compares, assesses, and chooses one verbal option over another in the process of lyricizing a given text for a designated modern audience (cf. Landers 2001:38-44).

Once such a poetic translation has been prepared, use of a computer (especially a portable laptop to permit easy physical movement) facilitates the subsequent text-testing and revision process. Thus the various poetic possibilities may be tried out (performed) and assessed in a number of ways with different individuals and potential groups of target-text consumers to determine the obvious instances or patterns of preference or disagreement, perhaps even outright rejection. The results may in turn be immediately recorded statistically along with the appropriate evaluative comments and recommendations for future stylistic modification and improvement (cf. Wendland 2004). More sophisticated computerbased applications can also be made for trial purposes, if so desired, such as shaping and conforming a given poetic text to fit an appropriate melody, one that has been either precomposed or generated on the spot by electronic means.

Finally, computer assisted procedures may be utilized in order to improve translator training methods with respect to the three distinct areas outlined above: data collection, text preparation, and poetic draft assessment. The pedagogical methodology may thus be streamlined, as well as individualized in order to make it communicatively more "relevant" and user-friendly in terms of efficiency (the time taken and effort expended to become 
"competent"), as well as effectiveness (the qualitative results achieved both during and at the end of the training process). The aim is to "prompt the poetic muse," so to speak - that is, to encourage and empower translators to utilize this new technology so that they might make more of a creative attempt to render biblical poetry idiomatically in the form of a functionally corresponding vernacular poetic genre. Some justification for a adopting a more innovative, domesticating approach, where situationally suitable, will be offered in passing (vis-à-vis a SL-oriented policy of "foreignization" or "resistance"; cf. Venuti 1998; also see Landers 2001:52-54 and the translational "acceptability model" of Bastin 2000).

\section{The Thematic 'Summit' of The Greatest Song}

The structurally distinct lyric found in Song of Songs 8:5b-7 is arguably the primary peak of the poet's literary expression of love. ${ }^{2}$ The Hebrew text of this artistically beautiful and rhetorically powerful passage reads as follows:

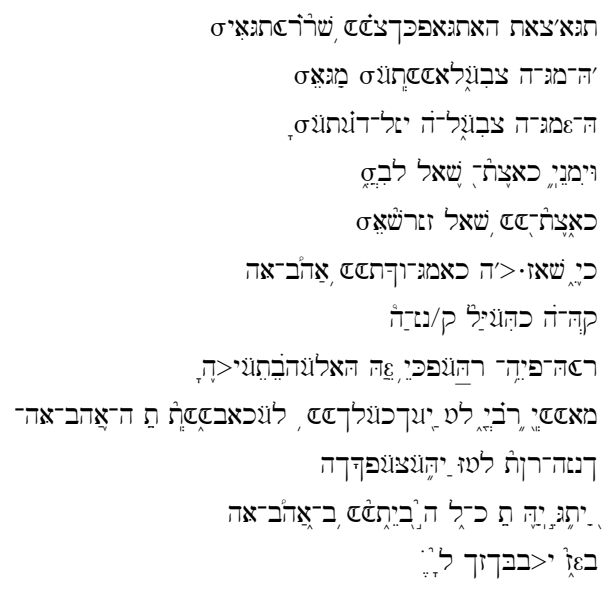

Before one can either generate or judge a given translation, one must first apply a critical eye to its original text. Beginning with the task of textual demarcation, we note that the onset of this pericope is delineated first of all by the formulaic closure of 8:3-4 (RSV):

${ }^{3} \mathrm{O}$ that his left hand were under my head, and that his right hand embraced me!

${ }^{4}$ I adjure you, O daughters of Jerusalem, that you stir not up nor awaken love until it pleases.

This distinct structural border is followed by an equally strong marker of aperture (commencement) in 8:5a, namely, the rhetorical question that duplicates 3:6a of structural segment 4 of the Song (an iterative compositional device termed anaphora; see also 6:10a).

${ }^{5}$ Who is that [fem.] coming up from the wilderness, leaning upon her beloved?

This question serves to fix the spotlight of attention (the oral-aural microphone as it were) upon the participant next referred to, in this case, the female speaker. She begins with a

The discussion here has been abbreviated; for a fully-referenced exegetical overview of this passage and the SoS as a whole, see Wendland 1995. 
figurative, allusive, and rather enigmatic description of her intimate relationship with her lover (8:5b; note the intratextuality, e.g., the "wake-up" call which reverses the choral prohibition of $2: 7 / 3: 5)$ :

Under the apple tree I awakened (or "aroused") you.

There your mother was in travail with you,

there she who bore you was in travail.

In the ancient near east, the topics of love and sexuality were often expressed figuratively using the imagery of fruit and fruit trees (cf. 2:3; "apple" - more likely, the apricot). Here, the female speaker picturesquely compares the birth and growth of love that she produced in her man to his mother giving birth to him. Assonance in the vowel-sound /a/ reinforces the point that it is the woman who is the main actor in this event (the object "you" $[-c h a]$ is masculine singular).

The preceding notice leads in verse 6 to a highly personal appeal for intimate proximity - not only physically, but the imagery would suggest socially as well, that is, in their communally and religiously sanctioned ("sealed") marriage vows (a development of the metaphor of 1:13). The "cylinder-seal" (or "signet-ring") symbolized personal identity and ownership along with connotations of preciousness and authority. The closeness of this amorous relationship is further reinforced by the metonymic figures of the "heart" and the "arm" (or "wrist"), to which such seals would always be most closely attached.

${ }^{6}$ Set me as a seal upon your heart, as a seal upon your arm;

for love is strong as death, jealousy is cruel as the grave.

Its flashes are flashes of fire, a most vehement flame.

The consequential "for" (kiy, more idiomatically: "for sure!") in the middle of v. 6 announces what sounds like a clear shift in the speaking voice - from the woman to the poet (implied author) as he proverbially expresses the point of the Song, which in Hebrew goes like this (followed by a very literal English translation):

$\begin{array}{lll}\text { For strong } & \text { like (the) death } & {[\text { is] love, }} \\ \text { unyielding } & \text { like Sheol } & {[\text { is] passion, }} \\ \text { its blazes the blazes of fire } & {[\text { like }]-} & \text { the flame of Yah[weh]! }\end{array}$

A host of Hebrew literary devices converge here to mark this passage as a high point (arguably the supreme peak) of the entire passionate discourse, which is also distinguished by means of a shift in genre, for the overtones of wisdom literature are obvious. Observe these poetic features, for example: strict parallelism (the first two lines); syntactic placement (the utterance-final key terms, "love" and "passion"); imagery (simile and metaphor); symbolism (death and fire); paradox (the compelling power of death [destructive] in contrast to love [creative]); condensation (especially the final line, where the fiery close is concentrated by an implicit marker of comparison); an ascending rhythmic pattern $(3+3+4)$ with variation (the extraordinary last word, or is it a half-line?); more assonance in [a] (to tie the text in to v. 5b); alliteration (the repeated [sh] of lines 2-3) with possible onomatopoeia (imaging the hissing of a fire); and finally, a possible cryptic mention of the

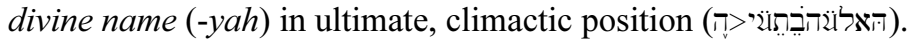


In verse 6 then we have the fullest, most sustained attempt to describe (or better, "evoke") the supreme subject of the Song, namely, paired male-female "love" (note the definite article of abstraction in v. 7). It is indeed a most irrepressible, irresistible, unquenchable force. Furthermore, the clipped and suffixed reference to "Yahweh," while it could be a mere idiomatic substitute for the superlative (i.e., the "hottest/brightest/purest" flame), in this structural position (cf. the equally unique "your name" in balance as a possible inclusio at 1:3) and in conjunction with so much stylistic embellishment, certainly seems to signify something more: Thus the final term shalhebet-yah "the flame of God" could well stand as the apex of the credo and of the Song. Yahweh is the Source not only of love in all its power and passion, but also of the marriage relationship in which affection is most completely and intimately experienced. Yahweh would surely appear to be present in this context (cf. the NJB, GW, and ASV), for fire is employed as a symbol of God's purifying presence throughout the Bible - here too then as the inexhaustible spark of a shared life of total devotion.

The subdued presence of the LORD in the single theophanic flash of a flame at this point towards the end of the Song contrasts also in implicit intertextuality with the contemporary love poetry of other cultures (e.g., Mowt "death" and Reshep "flames" in Ugaritic cultic texts). Such pagan poems made frequent mention of some local deity, often in conjunction with immoral, allegedly worshipful sexual activities. The apparent divergence in the case of the Song would thus seem to be indicative of a much different nature, purpose, and message.

There's still more of course: the poet does not finish in 8:6 but goes on in grand panegyric fashion to figuratively suggest the practical significance of "[this] love" (ha'ahaba, with still more accentuating assonance) in verse 7:

\footnotetext{
${ }^{7}$ Many waters cannot quench love, neither can floods drown it.

If a man offered for love all the wealth of his house, it would be utterly scorned.
}

From a mighty fire to a cosmic flood, a divinely motivated affection simply cannot be quenched. The allusions here need not be primarily mythological, for the psalmists had already dealt polemically with that issue through "defamiliarization" (citing a supposedly sacred alternative only to deny or downplay it) when proclaiming the almighty Lordship and mercy of Yahweh in caring for his people (e.g., Ps.18:6-16; 32:6; 93; cf., Exod. $15: 1-10)$. The imagery of water is especially relevant here due to the preceding references to the fiery passion of love. The extra-long cola of verse $7 \mathrm{a}$ and $7 \mathrm{c}$ mimic both the amplitude of the content and the rhythmic movement of the language, each concluding with the key word - "love".

This magnificent poetic depiction is rounded out in a more conventional wisdom fashion by means of a contrastive, probably ironic, reference to the proverbial "fool" who misunderstands and hence by implication also misuses personal affection. No price can purchase love. Such a misguided materialistic attitude deserves only "utter scorn" (an intensified boz yabuzu loh) from the society at large for polluting a godly gift (like the adulterer, who is severely punished for his desecration of love; cf. Prov.6:30-35). The strophe-final pronoun loh "to him" forms a homophonous (same-sounding) link with the preceding double occurrence of the negative $l o$ ' - "not/no". No self-seeking idiot can either buy or bar legitimate love! 
I will close this section by citing James Kugel's rendition of our central pericope taken from his selection of "the great poems of the Bible" (1999:274, added italics):

Make me a locket on your heart, a signet on your arm.

For love is as strong as death, and as harsh as Sheol.

Its flames burn like fire, a holy burning.

Deep waters can't put love out, and rivers will not drown it.

If a man gave all his family's wealth for love, would anybody blame him?

\section{The Poetic Reformulation of a Hebrew Love Poem}

Unless a translation team has the benefit of a skilled performing poet in their midst, the process of composing a poetic version of a biblical text will probably be something similar to the following procedure: The first task is to select an appropriate $T L$ genre to use as a translation model. This may have to be adapted in one respect or another to render it suitable for use in the Scriptures, especially if a public worship setting is envisaged. Often a mixed "oral-written" style is most effective for a printed text that will usually be presented in spoken form. This is what we tried to achieve in Chewa. ${ }^{3}$

The general lyric genre known as ndakatulo appears to be the most fitting and flexible enough to use in representing the diverse forms of biblical poetry, including the panegyric, petitionary, sapiential, and prophetic (judicial, homiletical, eschatological) subtypes. Chewa ndakatulo poems are characterized by the following ten crucial stylistic features (cf. Wendland 1993: chap. 3):

- balanced rhythmic lineation (with variation for special effect; there is no "meter")

- vivid imagery (especially similes and metaphors)

- graphic verbal ideophones (including sound symbolism)

- phonesthetic appeal (alliteration, assonance, selective rhyme, paronomasia)

- syntactic transposition (front- or backshift [e.g., away from S - V - O], clausal inversion within a sentence)

- special referential specification (featuring compound deictics)

- formal and semantic condensation (e.g., ellipsis) or expansion (e.g., reiteration)

- lexical intensification (including synonymy, affixes, and exclamations)

- dialogic dramatization (the prominence of direct speech)

- discourse architecture (text patterning by means of parallelism, inversions, reduplication, and contrastive juxtaposition)

However, it is not simply a matter of matching up feature for feature, or even genre for genre, in a mechanical sort of way, when translating any piece of excellent literature. There are two other important factors to consider, namely, the communicative function(s) and also the expressed emotions of the original text in relation to any TL genre or sub-genre that is selected to represent it. In other words, how is a particular TL poetic genre, including its associated stylistic devices, normally used in comparison with a given biblical text and with regard to such non-referential aspects of meaning?

\footnotetext{
By "we" I am referring to myself along with a succession of seminary classes that I have been privileged to interact with during a periodic Psalms exegetical course. The closing portion of this time of joint study and research is always devoted to an effort to compose selected psalm texts in the vernacular, employing a musical-choral form if possible. My students normally speak a variety of east-central Bantu languages in addition to English, and most are also able to refer to the original text of Scripture in Hebrew or Greek.
} 
In the case at hand, some extensive text research has revealed that the ndakatulo genre rather closely corresponds with the love poetry of the SoS in terms of several prominent communicative goals (Wendland 1993: chap. 4), in particular, the imperative, expressive, relational, and artistic motivations. Similar "speech acts" (a more specific functional perspective) are also performed, such as these: to complain, praise, encourage, rebuke, inspire, comfort, or warn someone. This makes a successful poetic trans-formation quite likely - if a skillful translator (or stylist) is available for the task, especially one with a clear inclination towards popular poetic expression in his or her mother tongue.

With a capable translator or translation team in place then, the next step is to fashion a "base text" that may be subsequently "poeticized" through the progressive application of various stylistic features that are typical of the genre that has been chosen to serve as a translation model. A question that applies in many translation settings, including Chewa, requires another key choice: Is it possible to adapt the text of an existing version for the model, or is it necessary in the interest of expediency to prepare a completely new translation?

In the present case one must evaluate what is already available to see if that will serve as a textual foundation to start from. Such an assessment exercise is carried out in limited fashion below with reference to the crucial core passage of $8: 6 \mathrm{~b}$. The first selection comes from the old (1923) Chewa "missionary version" and the second from the more recent (1997) "popular language" version. Relatively literal English back-translations are given after each selection:

A. Pakuti cikondi cilimba ngati imfa;
Njiru imangouma ngati manda:
Kung'anima kwace ndi kung'anima kwa moto,
Ngati mphenzi ya Yehova.

Because love is strong like death; Envy becomes hard like a grave: Its flashing is the flashing of fire, Like lightening of Jehovah.

\section{B. Paja chikondi nchamphamvu ngati imfa, nsanje njaliwuma ngati manda. Chikondi chimachita kuti lawilawi ngati malawi a moto, ndipo nchotentha koopsa.}

As you know, love is powerful like death, jealousy is stubborn like a grave.

Love often goes flash-flash! Like flames of fire, and it is terribly hot.

It would be very difficult to adapt anything on the basis of text $\mathbf{A}$ due to its literal unnaturalness, for example, its use of: the prosaic conjunction pakuti 'because'; a term with a strongly negative connotation, njiru 'envy'; syntactically linking the 'flashing' (kung 'anima) of 'lightning' (mphenzi) also with ordinary 'fire' (moto); and the difficult to understand descriptive expression 'its flashing is the flashing of fire'. Text $\mathbf{B}$ is considerably more intelligible and natural in style - but it does not really have a distinctive poetic sound. For instance, it does not feature a prevailing rhythmic flow, and there are not 
enough striking phonological effects - except for the combination of lawilawi 'flashing brightly' (an ideophone) and malawi 'flames'.

The preceding standard versions may now be compared with the independently composed poetic rendition that follows.

C. Kunena inetu, chikondi sichitha mpaka imfa; chayaka psi! monga moto uwala wa Chauta! Changu changa n'chouma gwa! ngati manda.

Well as for me, [my] love does not end until death; it's on fire, ashes! like the shining flame of the Creator! My zeal is rock-hard! just like the graveyard.

Here we might focus first on the Song's imagery, where the problem for translators concerns the challenge of giving a contemporary audience some idea of the overall significance of the many diverse, but related, figures of this text without overly explicating it, hence destroying its essential poetic nature. A certain amount of literary and cultural "contextualization" will undoubtedly be necessary in order to preserve the dynamic impact and esthetic dimension of the original when transferred to an appropriate indigenous lyric genre expressing interpersonal affection. But one cannot go too far in this regard with the result that the biblical situational and historical context is contradicted or important intertextual resonances are lost (e.g., vines/vineyards, cedars, sheep/goats, Lebanon, Mount Carmel, etc.).

One possible solution in such instances is the use of indigenous conventional figures which, due to their familiarity, have lost their immediate semantic reference and consequently convey rather an idealized impression of ardor and affection in the target language. Another option is to incorporate compact qualifiers that point listeners in the direction of a likely interpretation. We see examples of both solutions in the poetic text $\mathbf{C}$ :

Kunena inetu, chikondi sichitha mpaka imfa;

Well as for me, [my] love does not end until death;

(In Chewa, it is not natural to say that love is as "strong" as death; rather, true love "persists" until death.)

chayaka psi! monga moto uwala wa Chauta!

it's on fire, ashes! like the shining flame of Creator God!

(In Chewa the fire of love is described as "shining" like fire in order to eliminate the grounds of this simile that do not fit in this context, e.g., a destructive blaze or a fire for warming/cooking/lighting/etc.)

Other stylistic features in text $\mathbf{C}$ include: alliteration, assonance, rhyme, rhythm, intensive (self-) reference, descriptive ideophones, elaboration ("rock-hard" = resolute "zeal"), and balanced lineation.

\section{Computer Prompted and Perfected Poetry}

What was done then to compose passage $\mathbf{C}$ poetically - in other words, how was it possible to "prompt the poetic muse" here? More specifically, how did the computer facilitate this process of literary creation? Thinking back on my experience when composing not only this passage, but many others as well (a reflective translation "protocol"), eight procedures 
came to mind, as summarized and exemplified below. Another possible resource materialized later during my reading on the subject. A word processing program and other computerized tools may assist the poet-translator as follows: ${ }^{4}$

- The ease of composition on a computer, compared to long-hand writing, stimulates the smooth flow of ideas - that is, compositional fluency, with a minimum of delay or interruption between the mind and a page of print; similarly, all sorts of corrections and revisions (alterations, deletions, additions) can be swiftly carried out without having to rewrite an entire line, stanza, or page. ${ }^{5}$

- Words, phrases, and even entire lines can be quickly modified and moved, that is, shifted around within a document in order to create or improve the oral-aural sound dimension of the draft - that is, in terms of its rhythm, rhyme, alliteration, assonance, or paronomasia - while the poet actually utters and/or varies the text aloud.

- Syllables, words, and phrases can also be easily shifted about or replaced when weighing several translation options in the effort either to produce a more artistic ("poetic") style - or to return a dynamic text to a more accurate or acceptable level of exegetical fidelity.

- The lighted computer screen helps the eye to focus on chunks of text, rather than individual lines - an entire strophe or stanza in particular - thus promoting a consideration of the poetic whole as well as the constituent parts, with reference to the original text as well as its ongoing translation.

- Following on from the preceding point, different types of typography and format may be experimented with, both to attract the eyes of readers (to give it a more "poetic image" on the printed page) and also to make the passage more legible, with significant patches of empty space, thus rendering the text easier to enunciate aloud.

- Poetic drafts can be immediately and widely shared with colleagues to get their critical feedback and suggested improvements to the text; these may be inserted directly into the initial draft or indicated by the "track changes" function (Microsoft Word) for the original author to consider.

- Alternative drafts may be readily evaluated in relation to each other by means of a paratextual display that permits a close comparison of one poetic line and its distinctive stylistic features with its correspondent from another model text or version.

- An interlinear back-translation and a textual concordance for checking lexical consistency (or spelling inconsistencies!) can be prepared without much difficulty as tools for assisting the translation consultant and/or other technical advisers (e.g., exegetes),

4 I should also mention here some excellent electronic text-processing tools and translation helps such as Paratext and Translator's Workplace, which are most helpful when carrying out the tasks of source-text exegesis and target-text revision. However, in this paper I am focusing on computer aided techniques that are applied during the compositional process at a later stage (i.e., post-exegesis + preliminary draft) and for a special purpose, namely, the preparation of a specifically poetic version. This includes a subsequent "literary" assessment and text-polishing ("poeticizing") phase, which may be carried out as a joint team exercise by means of a computer network or multipoint work area.

5 Corresponding to the present point Qvale writes: "[T]he possibilities for infinite rewriting mean that one can allow oneself to find the best solutions without spending time removing text with the correction key or with correction fluid or x-ing over it. With a keystroke the PC corrects anything you type" (2003:255) - and it even shows you where you made basic spelling and grammatical errors! However, I (personally) do not agree with Qvale's subsequent observation: "[I]t is far more pleasant to sit in the sun with a manuscript pile proof reading and polishing. And here the pencil comes into its own..." (loc.cit). I happily remain seated behind my computer to carry on with these final text-finishing tasks! 
who may not have adequate command of the vernacular, so that they are able to make critical comments on a draft version in relation to the original poetic text.

- Finally (a resource not made use of during my poetic experiment), a computer makes it easy to access the Internet (especially via a "search engine" like Google) to connect with on-line reference websites and home pages as well as various hypertext programs or CD ROMs (e.g., the Encyclopedia Britannica, or the Translator's Workplace) in order to gain background material, including illustrations, concerning just about any subject imaginable. ${ }^{6}$ Such information sources may be tapped at any time during the compositional process, or when making a subsequent revision, as a means of improving the text in many major or minor ways that pertain to both form (style) and content. In addition, to obtain the answers to more specific questions, one can contact experts and research colleagues in a given field of study via topic-centered websites, bulletin boards, chat rooms, or e-mail discussion forums, for example, with regard to the Song of Songs, translating biblical poetry, or perhaps even modern Chewa ndakatulo lyrics.

All of these factors operate to greatly improve the overall process of text-composition: "...the translator can concentrate more fully and be more completely absorbed in and dedication (sic) to their work, which leads to a correspondingly improved translation" (Qvale 2003:256). ${ }^{7}$

I naturally referred to the existing translations ( $\mathbf{A}$ and $\mathbf{B}$ ) when drafting my own poetic rendition $(\mathbf{C})$. This was in addition to the Hebrew original text and several English translations, none of which were very helpful for my purposes. However, such a comparative exercise served to stimulate my thinking in terms of where problems existed, what modifications could be made, and how some new, more poetic expressions might be fashioned - that is, in keeping with the feature specifications for the ndakatulo lyric genre.

The first eight computer-aided procedures outlined above were selectively applied to the peak pericope of SoS 8:5b-7 to produce a series of draft translations that eventually resulted in the following "final" version, which is designed to reflect an idiomatic ndakatulo style. The compositional ease and flexibility of a word-processing program is especially helpful to a person like myself, who is not a "natural" (innate and spontaneous) poet in Chewa - or any other language for that matter - someone who works more by imitation of an ideal, rather than by artistic instinct. The computer is also helpful for producing a series of draft editions that can be read and critiqued by others (in my case, by mother-tongue seminary students) and then also for incorporating their recommended corrections and suggested improvements. Thus the text below is very much a composite work, the product of many minds - which is a useful analogy for Bible translation since it normally follows a similar method of team composition.

Some of the main poetic features that were introduced into the $\mathrm{C}$ strophe below (and distinct from versions A and B) are identified by brief descriptive-explanatory footnotes in the Chewa text and marked by underlining in the corresponding, relatively literal English back-translation:

6 "Hypertext is a term referring to a type of electronic document that contains cross-references and that rather than having a book's simple linear sequence is nonsequential, so that there are many different paths linking two elements in a hypertext structure" (Qvale 2003:259).

7 "On the other hand, some claim that many books become too long and prolix because the computer offers authors too little resistance. Authors correct and correct so incredibly easy that they lose their original style, lose the physical contact with the written word, lose the reflectiveness of pencil sharpening and the sobriety of dipping a nib into ink" (Qvale 2003:256). Speaking for myself, this has not been my experience; I do not miss pencil and ink at all! I rather appreciate the facility of being able to "correct and correct" my material so readily. 
Ine ndidakuyatsa mtima ${ }^{8}$ patsinde pa mango ${ }^{9}-$

uja mtengo ${ }^{10}$ adachirirapo ${ }^{11}$ amai pakubala iwe. ${ }^{12}$

Umatirire mtima $^{13}$ ndi chosindikiza chosalekeza ${ }^{14}$

kuti musalowedi winanso, koma ine ndekha. ${ }^{15}$

Kunena inetu, ${ }^{16}$ chikondi sichitha mpaka imfa,

Chayaka psi! $!^{17}$ monga moto uwala wa Chauta! ${ }^{18}$

\section{Changu changa n'chouma gwa! ${ }^{19}$ ngati manda.}

Chikondi chimenechi ${ }^{20}$ palibe madzi a chigumula angathe $^{21}$ kuchizimitsa kapena kuchikokolola, ai! $!^{22}$

Ngakhale ${ }^{23}$ munthu atapereka chuma chonse,

kufunitsitsa kugula chikondi choterechi, ${ }^{24}$

iyeyu adzangonyozeka nazo zyolizyoli! $!^{25}$
I aroused your heart at the base of that mango [tree], the very tree where your mother recovered in delivering you.

$\underline{\text { Fasten your heart with a seal that does }}$ not let go

lest any other enter there at all, except me alone.

Well as for me, [my] love does not end until death,

It's on fire, ashes! as the shining flame of the Creator!

My zeal is rock-hard! just like the graveyard.

A love like this, there are no

flood waters

able to put it out or sweep it away, not at all!

Even though a person were to give all [his] wealth,

trying his best to purchase a love of

this sort,

he would be fully embarrassed in the effort - for shame!

Idiom 'I set your heart on fire' - here, in terms of great affection.

"Mango" is a close local cultural substitute for the foreign "apple" and the unknown "apricot".

10 The double locative term in Hebrew ("there") is replaced by a twofold mention of the identifying "tree".

11 There is a translational loss here in that the original notion of "conception" is not mentioned - for the sake of cultural propriety (even for a youthful target audience!). On the other hand, an idiomatic, euphemistic expression for the child-delivery event is included - i.e., "she recovered [as from an injury or serious illness]". There is also an overlapping link-rhyme with mango and mtengo.

12 The first two balanced poetic lines (comprising a complete utterance) are also tied together by the pronominal inclusio: initial Ine "I" and final iwe "you".

13 A Chewa idiom is constructed here by analogy using the productive figurative base image of "heart" (mtima), which is close to the Hebrew expression.

14 The final two words of this line feature an alliterative combination.

15 A combination of emphatic features in Chewa highlight this added line which clarifies the implication of the original repeated Hebrew figure of the "seal - signet": verb gapping ("enter"), word order (subject-verb inversion), intensive suffixes (-di, -nso), and a final emphatic pronoun (ndekha), which in turn rhymes with the end of the preceding line.

16 The climactic line is set off and highlighted by this fronted casus pendens construction.

17 The ideophone $p s i$ ! suggests a scene of burnt up devastation, thus also hyperbolic here.

18 Assonance in the $/ a /$ vowel sounds helps foreground this entire line, which also makes explicit the allusive reference to YHWH (Chauta the traditional "High [Creator] God" of the Chewa people) in the original text. The last two lines of v. 6 are reversed in order so that the content flows more smoothly.

19 The ideophone gwa! (hard as a rock) is preceded by alliteration that stresses the key term changu "zeal", carrying over into the next line to aurally incorporate chikondi "love".

20 The front-shifted, hence emphasized, noun-demonstrative combination is further marked by the reiterated verbal infix -chi- in the next line, which is thereby more closely coupled to the former.

21 Enjambment syntactically mimics the flow of a flood - that cannot extinguish true love!

22 The final negative emphasizer (ai) is preceded by a pair of figurative verbal concepts: "put it out [like a fire]" and "sweep it away [as with a broom]".

23 The initial conjunction Ngakhale suggests that a more prosaic passage follows, as in the original Hebrew text.

24 More demonstrative marking, coupled with alliteration, links the key terms "love" (chikondi) and "wealth" (chuma). 
It is worth emphasizing the point here that most of the lyrical features that are manifested in the preceding passage were not present in the first translation drafts. They were incorporated later only after repeated readings and rewritings (see the example below). Such modifications are enabled - in fact encouraged - by the computer due to the ease with which it can manipulate a verbal text to achieve varied formal and functional effects involving the sense, significance, as well as aesthetic "style" of a poetic passage. This would be especially helpful when the poetry is being simultaneously composed to synchronize with a musical setting, an activity that modern computers can also coordinate quite easily. The artistic muse is thus electronically activated not only verbally (by way of Schprachgefühl), but also in terms of its resonant musical voice!

\section{Computer-assisted Poetic Composition through Text Corpora}

In this section and the next I will survey two systemic, also systematic, ways in which the use of a computer (more specifically, the appropriate word processing programs) might assist translators and their trainers in the rendering of poetic originals. They both involve the use of large compilations of electronic texts, or corpora (sg., corpus), when making a critical evaluation of the products of translation.

In so-called "corpus linguistics" a "text" is defined as "an instance of language in use, either spoken or written: a piece of language behavior which has occurred naturally..." (M. Stubbs, cited in Kenny 2001a:50), while a "corpus" consists of "a collection of texts held in machine-readable form and capable of being analysed automatically or semi-automatically in a variety of ways" (Baker 1995:225). In theoretical terms, corpus-based descriptive linguistics (and its various applications, as in translation studies) focuses on "what is probable in a language, according to the available evidence (i.e., parole), rather than what is possible (i.e., langue), according to a set of Chomsky-like a-priori rules" (Kenny 2001b:28, my additions in parentheses). This emphasis also distinguishes corpus linguistics from cognitive approaches that involve rather detailed descriptions of what individual analysts speculate concerning the logical strategies of language use, which are often based upon a minimal, even hypothetical, corpus of actual text material. ${ }^{26}$

There are three somewhat different types of corpora that are available in the major languages of the world (Baker 1995; Kenny 2001a:51-52; Kenny 2001b:ch.3):

- A parallel corpus is a twofold collection of texts consisting of documents originally written in language $\mathrm{X}$ together with their translations into language $\mathrm{Y}$.

- A multilingual corpus consists of original texts in a number of different languages $(\mathrm{X}, \mathrm{Y}, \mathrm{Z})$ that have been selected according to specific design criteria, e.g., text type, date(s), size, intended audience, and so forth.

- A comparable corpus of original texts written in language $X$, specified as to macro or micro-genre, in contrast to a collection of similar texts that have been translated into $\mathrm{X}$ from one or more other languages $(\mathrm{Y}, \mathrm{Z})$.

Most useful for literary and translational analysis and assessment in the present setting would appear to be the third ("comparable") category. This might include, for example, a set of originally composed Chewa poetic texts on the one hand, and on the other, extensive comparative samples of biblical poetry as translated in the three major published Bibles of

25 Several poetic devices converge to foreground the final plight of the foolish person who seeks to purchase "love": an initial emphatic pronoun, alliteration in $/ z /$, a phonologically coupled verb + ideophone combination (-nyozeka + zyolizyoli), and a final line rhyme with $/ i /$ sounds.

26 For a critique of such "mentalist" methodologies, see Yallop 2003:204. 
Chewa (perhaps including also the Bibles of closely related languages, such as Tumbuka or Sena).

However, any corpus is only as helpful as the amount of work that has gone into "preprocessing" it. A "raw" corpus is one that is neither tagged according to selected distinctive features nor grammatically parsed, but which manifests only minimal annotation, such as text, sectional, paragraph (strophe), sentence, clause, or line boundaries. The computer (word-processing) analysis of such a corpus can reveal such straightforward compositional features as lexical variety or redundancy, general semantic density (e.g., by removing all grammatical words), preferred lexical collocations, and average sentence or clause length. This is not very exciting, and an intuitive "feeling" for such characteristics could probably be gained simply by reading a great deal of text material over time. ${ }^{27}$

A linguistically "tagged" corpus on the other hand could be quite revealing, for example, to indicate prominent patterns of difference between original composition and translated material with regard to such features as the relative proportions of different parts of speech, phrase/clause/sentence types, preferred sentence structure, the kinds of external and internal transitional constructions, verb-sequence or tense-aspect patterns, and word order variations (including advancement to indicate "topic" and "focus"). Thus far, a number of corpus-based studies have revealed that "translated texts tend to be more explicit, unambiguous, and lexically or grammatically conventional than their source texts or other texts produced in the target language. They also tend to avoid repetitions that occur in the source text and to exaggerate features of the target language" (Kenny 2001a:52), such as compositional forms which are typical of a particular genre of literature or its translation into language $\mathrm{X}^{28}$

However, for the literary analysis of a poetic corpus, additional stylistic devices would need to be marked or designated somehow in the texts so that they could be quickly identified, sorted, numbered, and compared - for example, with respect to the occurrence of different types of figurative language (simile, metaphor, metonymy, personification, etc.), novel idioms, rhetorical and deliberative questions, dialectal terms, incorporated direct discourse, citations, rhetorical uses of hyperbole, exclamations, intensifiers, ideophones, extended attribution, and so forth. It is important to know not only the diversity and frequency of such literary characteristics, but also their distribution within individual texts would need to be noted, as well as an indication of certain important boundaries and peak points within a given discourse or set of texts of a particular genre. Unfortunately, however, I do not know of any significant corpus in any language, literary or otherwise, that has been tagged to such an explicit level of feature-specific detail. ${ }^{29}$

27 Qvale too notes that "[ $\mathrm{t}$ ]his sort of research [i.e., text corpus-based] depends on a large mass of material for analysis, to enable researchers to extract segments for computer analysis and comparison. However, there are big problems with sampling and programming, and one wonders whether the costs do not outweigh the benefits" (2003:252).

28 In a major computer-based analysis of lexical creativity in a corpus of German literary texts, Kenny concludes that "most of the time creative lexis in the source texts...is not normalized in translation, and some translators prove to be ingenious wordsmiths in their own right" (2001b:210) - the details of which need to be further investigated. On the other hand, "certain translators may be more inclined to normalize than others," for example, with respect to "text lexical features that draw on the more systematic processes of word formation in German - derivation and conversion to verbal nouns..." (ibid:211). Kenny ends her book with the candid observation that, generally speaking, "the findings of corpus-based studies are in some ways suggestions for future research" (loc. cit.).

29 I make a number of more specific suggestions concerning the possible application to Bible translation of computer-generated text data from corpora in Wendland 2003:227. 
To be sure, "computers offer new perspectives in the study of language... [allowing] us to see phenomena that previously remained obscure because of the limitations of our vantage points" (Kenny 2001b:xiii). Due to the concrete data that they produce with regard to a given corpus of texts, computers also make it possible for researchers to "corroborate, or repudiate, the findings of an initial study based on that corpus...[thus] stimulating multiple analyses and inviting researchers to constantly rethink their positions" (ibid:69). On the other hand, analysts must be aware of certain notable problems in connection with handling corpus-based computer-generated data. These include the following concerns:

- The emphasis on establishing statistically verifiable norms may lead to a tendency to ignore or downplay marginal or extraordinary cases and significant data that is represented only by a limited number of instances - the "exceptions" and "poetic" idiosyncrasies that are of special interest to literary practitioners and critics alike.

- The textual context, or "cotext," displayed by most computer generated concordances is not really sufficient to conduct anything more than superficial counts and simple collocational studies, which always need to be complemented by more expansive, discourse-oriented studies of the data. More sophisticated text-processing programs are proportionately more expensive.

- Quantitatively (statistically) supported text patterns and regularities provide a foundation, but cannot take the literary analyst and translation evaluator very far; such hard facts must always be complemented by qualitative, interpretive methods of analysis, like the comprehensive "close-reading" exercise that was carried out on SoS 8:5b-7.

- Finally, the general lack of availability with regard to any of these corpora, or text data bases, for the great majority of languages in the world, e.g., the whole Bantu family of Africa (let alone Chewa), presents a significant barrier to comparative analyses and assessments such as those described above; this is a serious obstacle that will not be easily overcome due to the lack of adequate financial resources and qualified staff.

With respect to the last point, I should note what I had available by way of a text corpus to use as a basis for comparison and as a source of possible examples to use in my poetic rendition of the SoS passage. My small collection consisted of six published booklets of Chewa ndakatulo poetry (spanning a period of over 30 years), plus a number of isolated instances. After they had all been manually keyed into the Microsoft Word program, ${ }^{30}$ the result totaled 128 pages (A4) of lined text (some 7000 poetic lines), 34,600 words, and approximately 200,000 characters. This is admittedly a rather diminutive database in comparison with the massive ones that are referred to in the literature on computer-based analysis, but my material does include at least $50 \%$ of all that has been published and is presently available in the Chewa language.

In any case, the corpus of raw text that I currently have available is of little use to me. Before I can meaningfully manipulate the data, all of the keyed-in material first needs to be tagged, or electronically marked, in some way with respect to the main features of ndakatulo lyric style so that they may be readily located for analytical purposes. This would be a very large assignment that can only be carried out successfully by well-trained mothertongue assistants, supported by a generous amount of financial assistance! It will be some time, therefore, before we will be able to prompt the poetic muse and benefit translators by means of this method.

30 I first tried scanning this material into the computer, but the process proved to be too prone to errors due to poor original copies. Perhaps a more sophisticated (and undoubtedly more expensive!) scanner would have solved my problem - at least in part. However, the print quality of a number of the booklets is probably not good enough to allow scanning on any machine. 


\section{Computer-assisted Training Techniques - Some Corpus-Based Possibilities}

In addition to compositional modeling and assessment, another critical area involving various types of text evaluation in the field of Bible translation that might be enhanced by corpus linguistics is in training programs. Due to the lack of a suitably tagged corpus of Chewa poetic texts, I have no direct experience of this. However, some interesting possibilities with respect to practical translation instruction are discussed in an article by Lynne Bowker published in a recent special edition of The Translator: Studies in Intercultural Communication (2000, sub-titled "Evaluation and translation"). Below I will briefly summarize what I see as the main implications of this well-documented study (listing only the page numbers by way of reference).

Bowker begins with the well-founded assertion that "evaluation is one of the most problematic areas of translation, having been variously described as 'a great stumbling block' ... 'a complex challenge' ... 'a most wretched question' ... and 'a thorny problem'" (183, internal references omitted). This is due to the largely subjective nature of such an endeavor due to the "fuzzy and shifting boundaries" of the notion of quality as well as "the lack of universally applicable criteria according to which translations may be assessed" (183). In an effort then to find a more objective and teachable approach to translation evaluation, Bowker proposes the use of a compound, electronic "Evaluation Corpus", the aim of which is to:

...act as a benchmark against which translator trainers can compare student translations on a number of different levels. By having access to a wide range of authentic and suitable texts, the trainer can verify or correct the students' choices, both conceptual and linguistic, and can provide more constructive and objective feedback based on evidence (or the lack thereof) in the corpus (184).

According to her definition (188), Bowker would employ a "multilingual" type of corpus for her translation assessment work, but it appears that a "comparable" corpus would serve the desired purpose better (see definitions above). A large corpus of varied texts in the TL would also do in this case. From either database then an Evaluation Corpus would be selected, consisting of three sub-corpora, which differ according to content and intended function as follows (191-194):

- The Quality Corpus is a small high-quality collection, consisting of texts that have been written by experts and chosen for their excellence of conceptual content and relative proximity in genre and subject matter to the primary source text (ST); this corpus is intended to help evaluate whether or not the student translators have correctly understood the key concepts and major themes of the ST.

- The Quantity Corpus is a much larger collection of texts dealing with the same subject as the ST and having a similar function; this corpus is intended to assist in the assessment of stylistic form, including the use of key terms and longer expressions, appropriate collocations, as well as discourse arrangements that are natural and characteristic of the semantic field and text-type in focus.

- The Inappropriate Corpus is a collection of texts that deal with the same general subject matter as the ST, but which are unsuitable as translation models in different respects, for example, in terms of compositional style, register, genre, terminology, discourse organization, format, and so forth; the aim of this corpus is to provide textual feedback to the student translators as to where they made errors or problematic choices in their own renditions of the ST. 
As a result of her research Bowker found that translation trainers (consultants) who made use of such an Evaluation Corpus technique were significantly more effective in their draft evaluation work with respect to both quantity and quality than colleagues who employed traditional methods of critical assessment. In addition, these evaluators were also appreciated more by the students themselves because their judgment was viewed as being more concrete, or "objective" in nature. Three qualitative criteria that might be assessed in particular are collocational appropriateness, the speed at which the translation in question is produced, and the terminological consistency of the translated text.

Although not tested directly in this study, the results seem to indicate that the studenttranslators themselves benefit from this corpus-based procedure when the Inappropriate Corpus is "used as a source of examples for discussing the appropriateness of different translations of the same text according to different briefs" (i.e., project terms of reference, 206) and as a stimulus for what Bastin terms "creative re-expression" in translator training exercises $(2000: 231){ }^{31}$ It is clear that computer generated technology can serve to facilitate the "three main techniques for stimulating creativity": associative conceptual "brainstorming", the temporary shift to a "parallel-activity" as a way to "overcome blockage", and as a means of "generating logical (certainly also connotative) alternatives" (ibid:243; addition in parentheses).

Either independently or as part of the preceding methodology, use of the "highlighting" option (and/or the colored-ink facility) coupled with the "track-changes" function of the Word program, for example, might be employed to display a succession of drafts with revisions as part of a computer-assisted training course (cf. Qvale 2003:252-3). As an illustration of this, ${ }^{32}$ consider our key passage, for example, in Song of Songs 8:6b. Proceeding from the "popular language" version (B) to the final poetic rendition (C), the "lyricization" process might be displayed as follows (where normal print represents the first/original draft, and additions during subsequent drafting are indicated by the following changes in the type format: second, third, and final draft):

1. (= B ) Paja chikondi nchamphamvu ngati imfa, nsanje njaliwuma ngati manda.

Chikondi chimachita kuti lawilawi ngati malawi a moto, ndipo nchotentha koopsa.

2.

Kunena inetu, chikondi sichitha mpaka imfa, nsanje njaliwuma ngati manda. Chikondi chimachita psi! ngati malawi a moto, ndipo nchotentha koopsa.

31 "If re-expression is to be better taught, evaluation of re-expression must be better thought" (ibid:231) - that is, by providing translators with more excellent models to follow in their work, whether that be a single text or an entire literary work (or Bible translation). Qvale offers this possibility: "Text corpus-based, computer-assisted research involving comparisons of different translators' rendering of the same text, for instance, may also be valuable aids to achieving insight into parts of the process" (2003:252).

32 My original paper was able to visually reproduce the sequence of "track-changes" operations, as well as the different colored shadings (to indicate different drafts) to demonstration the process of revision. This is not possible of course in a journal publication. 
3. Kunena inetu, chikondi sichitha mpaka imfa,

Changu changa n'chouma ngati manda.

Chayaka psi! ngati malawi a moto, ndipo nchotentha koopsa.

4. (=C) Kunena inetu, chikondi sichitha mpaka imfa,

Chayaka psi! ngati moto uwala wa Chauta.

Changu changa n'chouma ngati manda.

\begin{tabular}{|l|l|}
\hline DRAFT & Selective comments on each of the three revision drafts \\
\hline Second & $\begin{array}{l}\text { Paja sounds too prosaic for a lyric passage; replace with a transitional phrase } \\
\text { ('Well, as for me...'). A 'love' that 'does not end' is more idiomatic than 'is } \\
\text { powerful'. The ideophone psi! 'sustained burning' is more dynamic here than } \\
\text { lawilawi 'flashing intermittently'. }\end{array}$ \\
\hline Third & $\begin{array}{l}\text { The term nsanje 'envy' has a negative connotation; better to replace with } \\
\text { changu 'zeal'. Such zeal 'is hard' like a grave rather than 'stingy'. 'Love/zeal' } \\
\text { 'burns' - a more dynamic way to introduce the ideophone psi! }\end{array}$ \\
\hline Fourth & $\begin{array}{l}\text { Instead of 'like flames of fire', the revision tries to reflect the original (as } \\
\text { interpreted) more closely: 'like a shining fire of Chauta (Yahweh)'. The lines } \\
\text { of the text were reordered and condensed for rhythmic purposes and also to } \\
\text { render it more 'poetic"-sounding. }\end{array}$ \\
\hline
\end{tabular}

The track changes "comment" function can thus be utilized to raise queries, make corrections with explanations, and suggest some possible options in a very visible, easy-toread way (compared with an editor's hand-written scribbles on a typewritten text!).

Given the necessary provision (see Conclusion below), such computer-oriented methods might be readily adapted for use in the training of Bible translators, especially in the case of languages, like Chewa, that have at least a small literary tradition as well as a history of Bible translation. Since the Bible is sui generis, however, it would not be necessary to make use of a "Quality Corpus" with respect to religious content. Therefore, this database could be merged with the "Quantity Corpus" in order to provide some natural, idiomatic formal models to follow during the composition and evaluation of poetic vernacular texts. This corpus would be comprised of the collection of published secular ndakatulo texts, as mentioned earlier, as well as by other genres of Chewa discourse, both religious and secular. Because the available corpus of published (and available - in print!) texts is relatively small and since many of the same stylistic features are found in both prose and poetry, it may not be necessary to distinguish these basic types of literature, at least to begin with. Recognized "quality," as determined by a panel of experts, would be the only criterion necessary for inclusion in this corpus. Well-liked vernacular hymns or other types of lyric poetry, along with stylistically outstanding texts selected from the idiomatic "popular-language" version of the Bible (Buku Loyera), might be added to augment this general corpus of stylistic "Excellence" (to differentiate it from its opposite below).

An "Inappropriate Corpus" could then be formed from corresponding poetic excerpts taken from the other two literal, and missionary-dominated Chewa Bible translations, the Protestant Buku Lopatulika and the Catholic Malembo Oyera, as well as from stylistically mediocre or poorly structured texts selected from other (sub-)types of religious and secular literature, both original compositions and also translations. Translator trainees would be given the assignment of rendering a relatively large, but distinct pericope from the SoS, for 
example, and their respective drafts could then be compared respectively with the two "control" corpora (i.e., the "excellent" and the "inappropriate") in order to both evaluate the quality of their compositions and also instruct them as to where and how improvements might be made - with regard to either their individual texts or a composite "joint version" prepared jointly by a team.

\section{Conclusion}

Computer-assisted technology and the digitization of information have changed the theory and practice of translating, both globally and irreversibly. From one point of view, computer-assisted technology has brought only minimal and cosmetic change. Computers just help us work faster, smarter.

But from another point of view, computer-assisted technology and digitization have radically transformed not just the surface structure of this profession, but also its deep internal structures as well. And they have done so in ways that we only now begin to fathom, whether we are speaking of biblical, literary, technical, scientific, audio-visual, or multimedia translating (ICT-CAT Vision Statement).

My study, though very limited in its scope, would nevertheless lend support to the two major assertions that lie at the heart of the vision stated above - that is, concerning not only the practice, but also the theory of translation by means of computer-assisted translation.

Changes to the theory of translational art and science are at this stage not so easy to specify. I might suggest that the manifold "hypertext" as well as para-textual reference capacity of the computer makes it possible for the translator to readily display, compare, analyze, and network with several texts at once - that is, the source document and possibly one or more extant versions of that, whether drafts or previously published editions. Databases of model texts representing different genres of TL literature (or orature) and/or evaluation corpora like those discussed above could be quickly accessed (along with various types of supplementary background information) for contrastive examination, for example, to determine the relative degree of "equivalence" (or "similarity") with regard to selected features of interest. This multiple comparative compositional procedure coupled with an immediate access to topical resources not only promotes greater accuracy, but it also acts as a stimulus to the creative imagination, most notably in the case of a targeted literary (e.g., poetic) rendition.

The mutually stimulating influence of several similar, but also noticeably different, texts on the spontaneous cognitive and emotive activity of trans-forming texts cannot be minimized. In the language of cognitive poetics, more distinct "mental spaces" and consequent contextually-shaped "conceptual blending" (e.g., Coulson 2001:115-123) can be thereby generated simultaneously in a translator's mind and then also applied during the text-transfer operation. This makes the latter a complex, cyclical (or alternating), interactively creative process, rather than a more mechanically straightforward and linear conceptual exercise (i.e., rule-governed, procedure-dominated). Such a deliberate appeal to one's insight, interests, and intuition during the interlingual and intercultural exchange of texts will no doubt have some significant implications for the formulators of future translation theory, which we now expect will emerge first from the psycholinguistic and more innovative literary-sensitive branches of our discipline.

More obvious and immediate of course are the practical translational benefits of CAT. Indeed, the results of utilizing this electronic resource were exemplified above in terms of the Chewa poetic composition of SoS 8:5b-7. In addition to improved text-processing (synthesis), the computer's great potential in the key areas of draft evaluation (analysis) and 
translator training (pedagogy) has also been noted in passing. However, it is important to observe that the qualities of "faster" and "smarter" mentioned in the ICT-CAT prospectus above must be extended to include also a greater measure of accuracy - that is, "faithfulness," with respect to the original SL text, as well as "loyalty" in relation to the project sponsors and the brief which they initially formulated to guide the work. This issue is of special concern of course in the case of Scripture translation. These challenges too may be confronted by means of the great comparative facility that a computer makes possible, for example, with reference to the original text, to various translations of that same text, as well as to key translation models that may be used to stimulate and to direct an acceptable representation of the SL document in the TL. Prominent formal differences from the source document can thus be made to visually stand out (for example, by means of a paratextual, selectively-highlighted display) and then investigated for their significance in terms of different aspects of denotative and connotative (including also affective and aesthetic) meaning.

However, one final caveat (or two) needs to be reiterated in closing: As already suggested, there remain several critical impediments to the stated claim that "global" changes have (already) been effected or achieved by computer-based technology. It is a sobering fact that in many parts of the so-called "third world" the pronounced lack of technological development, computer-related resources (including their prohibitive cost for a majority of the population), experienced and capable teachers, modern training techniques and facilities, as well as other project-oriented limitations (e.g., time allocation, sufficient finances, a manifest desire or commitment on the part of program organizers, the requisite educational background, etc.) continue to muffle the voice of the poet in the realm of vernacular literary promotion in general and Bible translation in particular. A somewhat provocative question must therefore be asked in closing: $m$ ust this localized situation of deprivation and a consequent lack of achievement remain an "irreversible" status quo on the global scene, or can some realistic and workable solution be found to reverse it - in the interest of many depressed and endangered language-cultures worldwide? In short, why can the lyric voice of the poetic muse not be liberated everywhere, in Africa to be specific?

Lastly, now on a personal note, it may be necessary to point out that this oft-repressed poetic impulse cannot be compelled or cajoled to do the impossible. So, the next time you grapple with some challenging poetic text, you might recall the following advice: "If you notice that you are not succeeding, strike a blow for art [and give the muse a break]: Drop it! Give up and console yourself with the fact that a better translator will turn up, who will manage better than you.",33

33 Wolf Biermann, cited in Qvale 2003:267; added italics and material in brackets. 


\section{BIBLIOGRAPHY}

Baker, M 1995. "Corpora in translation studies: An overview and suggestions for future research." Target 7:2. 223-243.

Bastin, GL 2000. "Evaluating beginners' re-expression and creativity: A positive approach.” In Maier, C (ed.), The Translator (special issue) 6:2, 231-245.

Bowker, L 2000. "A corpus-based approach to evaluating student translations." In Maier C (ed.) q.v., 183-210.

Coulson, S 2001. Semantic leaps: Frame-shifting and conceptual blending in meaning construction. Cambridge: Cambridge UP.

Kenny, D 2001a. "Corpora in translation studies.” In Baker, M (ed.), Routledge encyclopedia of translation studies. London: Routledge. 50-53.

Kenny, D 2001b. Lexis and creativity in translation: A corpus-based study. Manchester: St. Jerome.

Kugel, JL 1999. The great poems of the Bible: A reader's companion with new translations. New York: The Free Press.

Landers, CE 2001. Literary translation: A practical guide. Clevedon, UK: Multilingual Matters.

Qvale, P, (trans.) Spencer, NR 2003. From St Jerome to hypertext: Translation in theory and practice. Manchester: St Jerome Publishing.

Venuti, L 1998. The scandals of translation: Towards an ethics of difference. London: Routledge.

Wendland, E 1993. Comparative discourse analysis and the translation of Psalm 22 in Chichewa, a Bantu language of south-central Africa. Lewiston, NY: Edwin Mellen Press.

Wendland, E 1995. "Seeking the path through a forest of symbols: A figurative and structural survey of the Song of Songs." Journal of Translation and Textlinguistics 7:2. 13-59.

Wendland, E 2003. "Responses to Colin Yallop lectures." Bible Translator 54:2. 225-228.

Wendland, E 2004. "What's the difference? Similarity (and disimilarity) from a crosscultural perspective: Some reflections upon the notion of 'acceptability' in Bible translation," in Hodgson, R and Arduini, S (eds.), Similarity and translation. Rome: Guaraldi Publishers. 329-358.

Yallop, C 2003. “On meaning, language, and culture.” The Bible Translator. 54:2. 202-225. 